\title{
Mourning and Melancholia
}

Claudia Lapping

\section{Chapter Summary}

The conceptual distinctions introduced in Freud's theorization of mourning, melancholia and melancholic identification can be used to open up the meaning of grief within the political field. Freud's observation of the visceral ambivalence associated with melancholia provides a basis for later theorizations of the fundamental passion or narcissistic wound that underlies both the intransigence and the unpredictability of forces associated with loss. His conceptualization of complex mechanisms of internalization of both lost objects and cultural prohibitions, provides a basis for exploring processes of repudiation of excluded or marginalized identities. His identification of contrasting processes of internalization and externalization helps us to map the contrasting ways political energies are directed in the aftermath of loss. Most crucially, his formulation of unconscious object loss as a way of explaining intensely painful affective processes guides our understanding of relations to loss as a psychical layer embedded within political and economic relations.

To explore the use of these ideas in political theory, this chapter examines a series of cases and suggests that it is important to distinguish between epistemology and the empirical exploration of a specific case. Epistemological arguments indicate some of the political risks involved in the representation of loss; but it is important to remain open minded in exploring unconscious relations to a particular instance of loss in the political field.

\section{(219 words)}

\section{Mourning and Melancholia}

State acts of recognition of responsibility for past atrocities are controversial, almost paradoxical, and inadequate in a most painful sense. From Willi Brandt's spontaneous gesture at the monument to the Warsaw Ghetto uprising, to the Japanese apology to the government of South Korea for sexual crimes committed by its military, to the UK government's acknowledgment that the Bloody Sunday killings were unjustifiable, and the South African truth and reconciliation commission hearings on violations committed under Apartheid. These acts require acknowledgement precisely because they are unspeakable, and the act of acknowledgment in no way captures the excess of the act that can't be seen or spoken. This inadequacy is repeated here, now, in written words that denote these events as if they are known, know-able or speak-able. Nevertheless, the fraught significance and inadequate weight of moments of state recognition signals something of the politics of loss, of the impossibility of shedding the past, and of the need to address in some way the ongoing resonances of the past in present political relations. Psychoanalytic conceptions of mourning and melancholia provide us with a way of conceptualizing the resonances of loss in the 
simultaneous constitution of individual and political identities. Their theorization of the unconscious dimensions of these identities, in the aftermath of loss, can help us to better understand the constitution of the political field.

With this aim in mind - the production of a better understanding of the constitution of the political field - this chapter explores the use of psychoanalytic understandings of mourning and melancholia in political theory and analysis. It sets out the multiple features of Freud's theorization of mourning, melancholia, and melancholic identification. It then traces ways contrasting aspects of Freud's account are elaborated in more recent discussion by Jean Laplance, Judith Butler, Derek Hook and Slavoj Zizek, and contrasting positions on the politics of resignification and the politics of the Thing. The implications of these theorisations are further explored in the presentation of a concrete instance: the Mitscherlichs' study of postwar Germany, The Inability to Mourn (1967). The chapter then focuses on studies in political theory that come under the broad headings of 'left melancholia' or 'feminist melancholia'. This is a body of writing analyzing the affective attachments underlying positions taken up within both political and academic fields, frequently staged as an opposition between more traditional Marxist/feminist approaches and poststructuralism. The final section introduces theorizations of the role of the witness in the aftermath of historical events associated with trauma. In looking across this range of instances of speculative and empirical analysis, the chapter argues for the importance of distinguishing between generalised epistemological arguments and the specific political potentialities associated with a particular case; and their contrasting roles in the interpretation of strategy and tactics in a politics of loss (c.f. Lacan, 1977; Hill, 2002).

\section{Mourning, melancholia and melancholic identification: Freud's early and later theorizations of loss}

The term 'mourning' is associated with bereavement, while 'melancholia' is associated with the symptoms of depression. In his initial theorization Freud elaborated the distinction between the two conditions in terms of unconscious relations to loss. His later work explored the wider implications of these relations. In reviewing the productivity of the concepts for political analysis, it is important to keep in mind the way in which the multiple features associated with each have been re-theorized both in Freud's own later work and in more contemporary engagements with his ideas. Recent work in politics, sociology and cultural studies can perhaps be understood in relation to the identifications they articulate with distinct interpretations of specific conceptual elements of Freud's theories.

Freud's conceptualization of melancholia is based on an analogy he constructs between patients mourning bereavement and patients exhibiting symptoms of melancholy. He notes the similarity in the 'painful frame of mind', 'loss of interest in the outside world' and the 'loss of the capacity to love' (1957:244) that characterizes both conditions. However he notes with curiosity that fact that while the unusual pain associated with mourning is considered an understandable response to a visible loss, the prolonged distress experienced in cases of 
melancholia is treated as pathological and in need of explanation. Freud suggests that further exploration of the analogy between the two might make each more intelligible. The comparison is the basis for his theorization of the unconscious relations within both conditions, and for his conceptualization of a 'lost object' within processes of melancholy.

The metaphor of the 'lost object' can help us to account for cases where the 'mourning' is not for someone who has died, and also for cases where 'one cannot clearly see what it is that has been lost'. Freud suggests, for example, that in cases where this 'loss' is ideal rather than actual, 'it is all the more reasonable to suppose that the patient cannot consciously perceive what he has lost either' (1957:245). This unperceived or unconscious status of the loss blurs the distinction between the external and internal world, and suggests a certain emptiness of the ego. He says: 'In mourning it is the world which has become poor and empty; in melancholia it is the ego itself' (246), and the distinction between externalized and internalized loss is significant. Freud suggests that in mourning the ego is able to detach itself from the lost object through a process of reality checking: 'Each individual memory and expectation in which the libido was connected to the object is adjusted and hyper invested, leading to detachment from the libido'. In melancholia, in contrast, the lost object is internalized and becomes a constitutive element of the ego. He describes melancholia as an acutely painful and unresolved form of mourning, associated with 'self-reproaches', 'self revilings' and 'a delusional expectation of punishment'. This attack on the self distinguishes melancholia from mourning in which, he says, 'the disturbance of self regard is absent' (Freud, 1957:244).

The self-reproaches associated with melancholia, Freud says, can frequently be understood as identifications with the loved object:

If one listens patiently to a melancholic's many and various self-accusations, one cannot in the end avoid the impression that often the most violent of them are hardly at all applicable to the patient himself, but that with insignificant modifications they do fit someone else, someone whom the patient loves, or has loved, or should love.

(248)

He concludes, 'the self reproaches are reproaches against a loved object which have been shifted away from it on to the patient's own ego'. Through these identifications, the features associated with the lost object are internalised by the ego, and the emotions directed at the object are turned inwards, creating a split within the ego between the internalised object and the critical emotions the ego directs at it. Freud suggests an ongoing struggle in which the ego fights both to detach from the object and also to maintain the strong emotional attachment. The ambiguity in the loved/hated nature of the lost object, and the failure to detach from the object cause of melancholia thus creates a visceral ambivalence in the relation between the 
object and the ego; or, to be more precise, the ambivalence persists in the relation between the internalization of the object and the other elements of the ego.

In his later work, The Ego and the Id (1923), however, Freud speculates that, rather than being a feature that distinguishes melancholia from mourning, the internalization of the object might be a common feature of the two states: 'It might be that this identification is the sole condition under which the id can give up its objects' (29). Building on this extension of his understanding of melancholic processes, Freud suggests that the identification with a lost object is far more significant than he had originally suggested. He speculates that this melancholic process plays a part in the construction of the super ego, which is instantiated in the first identifications of the subject. The simultaneous formation of the subject and the super ego takes place during the Oedipus conflict, in which the child is forced to give up their polymorphous desire for the mother and to identify with (one of) their parents, thus taking on a sexual identity (p. 34). These identifications instantiate the influence of the parents and of wider social and moral obligations within the child:

The child's parents, and especially his father, were perceived as the obstacle to a realization of his Oedipus wishes; so his infantile ego fortified itself for the carrying out of the repression by erecting the same obstacle within itself.

(ibid, p. 34)

Freud notes that this formulation constitutes an alteration in the conceptual structure of melancholia: 'these identifications', he says, 'are not what we would have expected' (p. 32). Instead of an internalisation of the object, there is an internalisation of the prohibition of the object, and this is the basis of the super-ego. This development, Freud says, begins to suggest the 'full significance' (p. 28) of melancholic identifications and of the role they play in the formation of the ego.

There are several significant distinctions within Freud's accounts. There is the distinction between a process in which the subject is able to detach from the lost object and a process in which the relation to the object is sustained, in some form, within the ego. There is the distinction between the internalisation of the lost object within the ego and the internalisation of the prohibition of the object. And there is the distinction between melancholia as a pathological process and melancholic identification as the common basis for the formation of the subject.

\section{Recent elaborations of Freud's concepts mourning and melancholia for political analysis} Contemporary theorists, Jean Laplanche, Judith Butler, Derek Hook and Slavoj Zizek, have developed contrasting aspects of Freud's conceptualizations of mourning and melancholia. Their elaborations foreground contrasting political implications of his ideas. 
Laplanche engages with Freud's suggestion in his earlier paper that the loss associated with mourning is both understandable and conscious:

Where are we to find mourning which would only be conscious, with no infantile reverberation, no ambivalence and no narcissistic consequences? [...] If mourning, in fact, entails no narcissistic wound, no breaching of the ego, how can it be understood to be so painful?' (1999:249).

He draws attention to impossibility of a fully conscious experience of loss, and associates this with the extremity of pain associated with mourning, since this pain can only be understood through the theorization of a viscerally significant, unconscious or unspeakable, aspect of the affective attachment to the object. The foregrounding of the narcissistic wound associated with unconscious loss is suggestive for the analysis of visceral political and cultural relations. As Freud had noted in his later work, significant aspects of the relation to the lost object may be common in mourning, melancholia and in processes of melancholic identification.

Butler elaborates further the political implications of the processes of unconscious melancholic identifications that Freud theorized in his later work as inherent to the process of becoming a subject. She extends this idea to theorize the possibility that identification with a lost object may be the basis for the cultural and political prohibition of certain identities and attachments:

In The Ego and the Id, [Freud] makes room for the notion that melancholic identification may be a prerequisite for letting the object go. By claiming this, he changes what it means to "let an object go," for there is no final breaking of the attachment. There is, rather, the incorporation of the attachment as identification, where identification becomes a magical, a psychic form of preserving the object. Insofar as identification is the psychic preserve of the object and such identifications come to form the ego, the lost object continues to haunt and inhabit the ego as one of its constitutive identifications. The lost object is, in that sense, made coextensive with the ego itself. Indeed, one might conclude that melancholic identification permits the loss of the object in the external world precisely because it provides a way to preserve the object as part of the ego, and, hence, to avert the loss as a complete loss. Giving up the object becomes possible only on the condition of a melancholic internalization (1997:134)

The distinction between the melancholic internalization of loss and the externalization embodied in processes of mourning is significant for the politics of melancholia: 'If the object can no longer exist in the external world, it will then exist internally, and that internalization will be a way to disavow the loss, to keep it at bay, to stay or postpone the recognition and suffering of loss' (134). She identifies this pathological melancholic internalization in the 
hyperbolic masculine identifications that are associated with a foreclosure of homosexual attachment. This political extension of Freud's idea, she suggests, points to the need for cultural practices of mourning to re-introduce or re-signify the lost or obliterated object of repudiated identities. Key here is the risk that internalization acts as a corollary or support for the exclusionary cultural or social prohibition of the object.

Zizek (2000) introduces a further distinction into the political mapping of melancholic relations. He foregrounds the impossibility of bringing the object of melancholic yearning into discourse: 'In short, what melancholy obfuscates is that the object is lacking from the very beginning, that its emergence coincides with its lack, that this object is nothing but the positivization of a void or lack' (660). This clarification is in line with Butler's careful delineation of the status of the object. She is mindful of contrasting modes unconscious loss (1997:139), although it is also worth noting that Derek Hook, in his reiteration of Freudian distinctions between mourning, melancholic identification and the pathological condition of melancholia, criticizes her for overgeneralization in her account of the foreclosure of homosexual attachment. Hook argues for the need to avoid generalizations about states of cultural melancholia, and to pay attention to the singularity of both historical circumstance and individual subjects' relations to loss: 'As in psychoanalytic treatment, one needs to attend not only to given socio-historical circumstances but the singularity of the given subject's (or subject community's) responses to such circumstances, as set of responses that never fit the answer that theory would predispose us to expect.' (2014:no pages). The aspect of the object, or the lack in the object, that resonates with or constitutes the subject's narcissistic wound is not to be known in advance, if it is to be known at all. In slightly different ways both Zizek and Hook point to the epistemological and empirical impossibility of representing the object of loss.

In addition, Hook and Zizek, perhaps more vehemently than Butler, foreground the risk of conceptualizing melancholic internalization as a productive way of preserving a socially repudiated object, citing the way this has been proposed in some recent cultural analyses. Eng and Han, for example, in an exploration of the intersections of clinical and cultural/politics, note the danger of the way melancholic internalization of loss 'threatens to render the social invisible' (2003:355). Nevertheless, drawing on a Kleinian understanding of the significance of internal objects in relation to individual psychical pain, they argue that in clinical work the preservation of the lost object may sometimes be an ethical necessity (362). They also, further, suggest that the melancholic internalization of the lost object may be associated with a productive politics of preservation: 'the melancholic process is one way in which socially disparaged objects - racially and sexually disprivileged others - live on in the psychic realm' (364). They cite Butler's reference to the 'psychic violence of conscience' as an indictment of exclusionary social formations, and speculate that there may be potentially productive, truth telling energies associated with melancholic internalization. 
For Hook, in contrast, it is important to maintain a distinction between the unconscious preservation of loss associated with melancholia and the gradual differentiation of the ego from the object brought about in acts of mourning and cultural remembrance. The painful self-reviling constituted in the melancholic attack on the internalized lost object, he suggests, risks turning back on the subject if there is cultural preservation without differentiation (2014). Zizek thematises this risk in the quest for cultural ownership of an object that might fix an identity in place:

The melancholic link to the lost ethnic Object allows us to claim that we remain faithful to our ethnic roots while fully participating in the global capitalist game. (2000:659).

Here he foregrounds the way the object associated with a repudiated identity is always constituted by an already exclusionary social and economic system. He opposes the internalized attachment to a fixed cultural identity to an ethics of the unknowable: 'the unconditional fidelity to the Otherness of the Thing that disrupts the entire social edifice' (666). The 'Thing' here refers to an absolutely unknowable force that drives symbolization, described by Lacan as 'the cause of the most fundamental human passions' (cited in Evans, 1996:205). Thus, Zizek suggests, the preservation of a relation to an internalized object of loss covers over this fundamental driving force that constitutes lack both in the object and in the social conditions of its repudiation: the ethnic object is defined within a specific economic system, the symbolization of which disguises the cause of the passions out of which it is constituted. For Zizek this delegitimizes any process that, in its preservation of the object, also maintains existing economic and symbolic relations to the object, while denying the unimaginably excessive cause of those relations. The alternative is a political act in which the subject embodies the monstrosity of the Thing, the excessive un-nameable aspect of the notobject that is unspeakable, and that may be capable of disturbing the social fabric (669).

This conceptual terrain gives rise to a series of questions. What are the implications of Laplanche's suggestion that the unconscious trace of the lost object relates to a narcissistic wound? Might some form of cultural articulation of that trace serve as a political gesture against oppression/obliteration? Or does the conscious cultural preservation of the object necessarily constitute a reifying act of reparation with the social conditions of lack that brought about the imagined loss? What might it mean, politically or empirically, to take the position of the Thing? As Derek Hook (ibid) points out the specific and varied texture of any instance of loss make it impossible to predict in advance its political and psychical effects. With this in mind, before moving on to look at discussions of feminist and left melancholia in political theory, in the next section I draw on the Mitscherlichs' classic sociological/psychosocial study of post-war Germany, in order to set out the conceptual terms in slightly more concrete form. 
Interpreting the lost object: methodological and political implications of The Inability to Mourn

Mitscherlich and Mitscherlich's classic study of post war Germany, The Inability to Mourn (1975) is a major early contribution to the field. Methodologically I want to draw attention to the range of evidence the authors deploy in the study to interpret processes of mourning or of the failure to mourn. Conceptually I want to foreground shifting interpretations of the 'lost object' and instances of redirection of libidinal energies that are traced in their study. Politically, there is a question about the role a process of mourning might play in bringing about a recognition or resignification of loss.

The Mitscherlichs' study begins with the observation that despite the mass involvement in the Nazi movement, from membership of Hitler Youth to active service in the SS or the German army, there was little evidence of guilt or depression following the defeat of Hitler and the exposure of the extent of the Nazi atrocities. They argue:

That so few signs of melancholia or even of mourning are to be seen among the great masses of the population can be attributed only to a collective denial of the past. (1975:

28)

Their study traces the different mechanisms of denial within economic and cultural activity as well as within case studies of patients in clinical psychoanalytic practice.

As evidence of cultural denial the Mitscherlichs cite the commemoration of German losses in the bombings of Dresden and Frankfurt, but the lack of any comparable memorial of the victims of the concentration camps (30); they note the sustained readership for "books and newspaper articles claiming that what was done was done under pressure from evil persecutors' (16); they contrast a newspaper notice celebrating the birthday of a professor who served in the Nazi government with the continuing negative reactions to the few who resisted the regime (51-3); and they point to the lack of historical studies of the Nazi period by West German scholars (53). In the sphere of political and economic activity the Mitscherlichs' argue that the refusal of West Germany to give up its claims to the territories of East Germany constituted a denial of the realities of their defeat (5). They point to an associated diversion of libidinal energy from the field of politics to the field of industry and consumerism (9) and suggest this industrious diversion of energy constitutes a 'manic defense' by means of which to 'obliterate the past' (15). As a corollary of these processes, the Mitscherlichs point to the 'theory of enforced obedience' whereby the leaders of the Nazi regime, who had previously been the object of attachment and idealization, 'were alone responsible for putting genocide into practice' (15). This redirection of libidinal energy appears to keep at bay the more painful response to loss whereby the object is internalized and guilt and self-reproach are turned inwards. 
Alongside their analysis of the cultural and political landscape the Mitscherlichs present three case studies of patients in clinical psychoanalysis. Two of these patients, they suggest, presented themselves as the victim in relation to the war, one describing the German people as a whole as suffering great wrongs, the other blaming his fellow countrymen for robbing him of his pride in his nation. The third patient, who said he had never been a convinced Nazi despite serving as an officer during the war, recalled memories of compliance during the process of his analysis. The Mitscherlichs point to the significance both of the repression of these memories, and also of the fact that, in a way that was not typical of this patient, the recollections were apparently not accompanied by any strong affective response. They interpret this lack of affect as indicative of the cultural context, as it did not seem to be explicable solely in relation to the patient's individual resistance. This suggests that individual mechanisms of denial are supported by the network of denials in the cultural and political sphere, and as such might be understood as 'a collectively approved resistance' (italics in original: 35$)$.

The consistency of the denials of guilt or responsibility across cultural, political and clinical instances constitutes a persuasive picture of a collective inability to acknowledge the losses associated with the war. However, the object of loss shifts: at some points it appears as the loss of a powerful leader, at others it is the loss of national pride and guilt-free identity. There is little direct evidence of any sense of a loss associated with the enactment or victims of Nazi atrocities. In most instances, the evidence from the cultural field indicates the way cultural and psychical mechanisms of denial are reinforced, while the clinical evidence helps to confirm an unconscious dimension of a loss that is being denied. While mindful of Hook's caution against generalization, it would certainly be possible to conceptualize this as a type of foreclosure, a loss of an object that never existed as such - not because the atrocities never happened, but because they are impossible to perceive or to conceive - the magnitude of the horror is simply too great. Politically, from a more Butlerian perspective, in line with the Mitscherlichs, this might indicate the need for a visible process of mourning, to find a mode of recognition or signification of the object within discourse. A Zizekian approach might, rather, foreground the impossibility of ever naming, or of bringing into discourse, the criminality and trauma of the holocaust. The attempt to reconcile through a process of cultural resignification, Zizek's argument might suggest, risks in some sense cleansing or acquitting the social edifice from which the atrocity emerged.

The opposition constructed here concerns political strategy: a cultural politics of resignification is opposed to a more direct confrontation of the economic and political field with the Thing it cannot see. Empirically, though, it may not be possible to know in advance when these apparently, or epistemologically, distinct strategies may either come into conflict or coincide. This undecidable mess is what intrigues the empirical social scientist. In empirical work, psychoanalysis adds a layer to analyses of specific social, economic and political relations, and to our (mis)understanding of the complexity of these relations. Applications of 
psychoanalytic ideas in the field of political theory work slightly differently. Here psychoanalytic conceptions of mourning and melancholia are used to insert a more generalized and speculative interpretation of the unconscious into existing theorizations of the political field. The level of specificity or generality varies from case to case, and even highly generalized and speculative interpretations of unconscious attachment might be understood as a starting point for a reflexive process of 'reality checking' to work though sedimented ideas.

Affective force within the political left: interpreting melancholic processes in Political and Feminist Theory

In 1990 Helmut Dubiel wrote 'Beyond Mourning and Melancholy of the Left', an analysis of positions emerging in writing on the German academic left following reunification and the collapse of the GDR. Dubiel's object of analysis is a body texts by a West German left wing intelligentsia who had struggled to maintain a position between the anti-communism that dominated social science departments in the Federal Republic and the totalitarian socialism of the East (1990:243). His analysis distinguishes a postmodern approach that 'sacrifices leftist identity altogether' from authors whose 'first concern is preserving their own identity' (241). He interprets these positions using Freud's initial distinction between mourning and melancholia, and his account of the need for a process of reality testing to work through and come to terms with loss. Neither camp, Dubiel argues, has understood or worked through the meaning of the loss of an empirically existing, if repudiated, alternative to capitalism. He identifies the postmodern position as a manic attempt to detach from the libidinal investments in this utopian alternative; while the reiterations of an unaltered vocabulary of empirical socialism suggest a persistent melancholic inwardness and failure to detach (242). Of the latter group he suggests: 'That empirical socialism became the target for the projection of leftist hopes in the West just as it was disappearing proves that interpretational patterns still stored in the unconscious of many leftists had become linked to its mere existence' (244). His own interpretation suggests: 'Nothing distinguished totalitarian socialism other than its sheer existence, other than the fact that it embodied the possibility that capitalism could be subject to a beyond' (243).

Dubiel's response is to attempt to construct a process of mourning by subjecting the reified terms of socialism to a process of reality testing, to gradually release the libidinal investment and re-engage with the world. He argues for the need to scrutinize all elements of the traditionalist socialist model in the light of contemporary economic and political developments: new technologies and speculative financial cycles, critiques of progress narratives and vanguardist models of revolution, and contemporary understandings of pluralism that put into question both authoritarian universalism and unreflexive analyses of the division of labour (244-8; see also Jay, 1992). His overall argument is for an understanding that capitalism 'is not an order identical with itself' (248) and suggests that a working through of the terms of socialism is necessary to reactivate left politics: 'civilizing capitalism to the 
point that it is no longer recognizable' (249). This formulation, it might be argued, can be interpreted through both a Butlerian lens of articulation and resignification and a Zizekian conception of impossibility and flux.

The terms of Dubiel's analysis are mirrored and extended in recent debates tracing the ongoing struggles of the left (Brown, 1999; Dean, 2012). Wendy Brown offers a similar contextual positioning of these struggles in the loss of unified movements, the delegitimization of class analyses, and the loss of narratives of progress. Also in line with Dubiel, she suggests a more painful unavowed loss is the loss of a feeling: 'the promise that left analysis and left commitment would supply its adherents a clear and certain path toward the good, the right and the true'. Citing Freud's analysis of the way hatred for the lost object is sadistically redirected, she argues that it is the loss of this idealized promise that drives divisions in the left, and the disproportionate wrath directed toward both identity politics and poststructuralism (22-3). Drawing on the work of Stuart Hall, she argues that the traditionalist left's refusal to extend its interpretive vocabulary means it has failed to meet the challenge of the new Right's construction of a discourse that links 'privatization' to political logics associated with increased sexual and cultural diversification. In contrast, she argues, the left clings to a narrow vocabulary of the welfare state and defense of civil liberties: 'the Left has come to represent a politics that seeks to protect a set of freedoms and entitlements that confronts neither the dominations contained in both nor the limited value of those freedoms and entitlements in contemporary configurations of capitalism' (26). Drawing on Benjamin's conceptualization of 'left melancholia' as a sentimental attachment to a feeling that blocks engagement with the world, she thus argues that the left is failing to develop the necessary critique of contemporary capitalism. Jodi Dean inflects this analysis with the observation that this disarmed politics might also be understood as a manic redirection of revolutionary desire: 'Instead of a Left attached to an unacknowledged orthodoxy, we have one that has given way on the desire for communism, betrayed its historical commitment to the proletariat, and sublimated revolutionary energies into restorationist practices that strengthen the hold of capitalism' (2012:174; see also Segal, 2003:144-5).

It is important also to trace productive delineations of these ideas within feminist theory, where regretful responses to shifts in feminist theoretical discourse, in the institutionalization and professionalization of feminism and in the relation between feminist epistemology and feminist activism, have been interpreted through the lens of melancholia (e.g. Wiegman, 2000; Roy, 2009). Wiegman, echoing aspects of Dubiel's and Brown's analyses, argues that 'feminism is not self-identical' (808) and that attempts to construct a unified feminist tradition risk imposing prescriptive norms on the development of feminist knowledge. She re-theorizes analyses of left melancholia, in the context of feminism, as an apocalyptic anxiety provoked 'less by an overwhelming sense of past loss than by a fear about the failure of the future' (807). This anxiety, she argues, is associated with an attachment to a teleological narrative of a feminist time that is rooted in spontaneous origins, but that defines the present in relation 
to the legacy of earlier generations. 'Generational legacy' she argues, 'operates through a strategic foreclosure of the possibility of existing in time with new and radically discontinuous modes of spontaneous generation' (811). Wiegman's analysis also constructs a space of articulation with Dean's call for the left to be faithful to impossible desire as opposed to allowing ourselves to be captured by activities that 'feel productive, important and radical' (2012:176), which resonates with Wiegman's analysis of regretful responses to increasing fissures between feminist activism and feminist theory. As an alternative to regret she traces a painful space for a politics of the impossible: 'I hope to inhabit the anxiety that the apocalyptic speaks without either capitulating to it (and hence declaring feminism is dead) or disciplining it (and hence declaring the present as fully productive to feminism's future time)' (2000:815). Although offering contrasting formulations, all these authors foreground the risk of attachment to a political and temporal positivity as a significant feature of contemporary melancholic politics.

These studies use speculative theoretical analysis to map different points at which it might be possible to interpret unconscious forces in a field of political positions. Although, as Dubiel notes (1990:242; see also Segal, 2003:151) the speculative methodology means that claims remain at a rhetorical level of generality, together the studies constitute a rich account of possible moments of unconscious attachment. In addition, as instances of the field that is their object of analysis, the contrasting ways in which they interpret the objects of attachment (e.g. contrasting interpretations of 'authoritarianism' and 'utopianism' in Dean, 2012:175, and Dubiel, 1990:246) mark the texts themselves as libidinally invested subjective articulations. Each text seems to have a dual purpose, both as an analysis of the field and as a position within the field. There is, then, perhaps a question about the extent to which they might be interpreted as attempts to engage in a productive working through of injurious loss. This raises further questions about the conscious and unconscious affect associated with political attachments, about the way the loss of such attachments marks political subjectivities, and about clinical and non-clinical approaches to working through the ongoing political effects of such loss.

\section{Bearing witness to trauma: a politics of resignification and a politics of the Thing}

In the previous sections l've discussed work that explores the unconscious delineation and effects of loss. Here I consider the question of traumatic loss from a slightly different perspective. To do this I draw on Samuel Gerson's discussion of the concept of the third, the role of a 'live third' or witness in maintaining the subject, and an understanding of trauma as the loss of this life giving relation. He says:

I apply the notion of the third to that entity - be it personal, social or cultural - that exists in relation to an individual and his or her experience of massive trauma. The concept of the witness is used as an exemplar of a 'live third' - simply put this is the other whose engaged recognition and concerned responsiveness to the individual's 
experience create livable meaning. The 'dead third' is conceptualized as the loss of a 'live third' on whom the individual had previously relied, had entrusted with faith, and in relation to whom or which, had developed a sense of personal continuity and meaning. (2009:1343)

Gerson's account encompasses a variety of conceptions of third-ness: a developmental conception of the oedipal third, a relational conception of an intersubjective or analytic third, and what he calls a 'cultural third', social, linguistic and cultural formations that, in his words 'exert a powerful influence on the structures of thought and affect' (1342). Trauma, he suggests, following Freud, is less about the 'degree of excess stimulation' (1345) than it is about the loss of a third in relation to whom, or which, the subject makes sense of their being. He formulates this as 'the overwhelming experience of learning that there is an absence of concern about ones plight' (1345). With this understanding of the role of the third in the trauma of the subject, Gerson's aim is to explore the possibility of relieving the effects of such trauma. He suggests: 'We have all come to recognize that the most basic necessity for psychic aliveness in the aftermath of atrocity is the active witnessing presence of an other' (1353). Gerson's paper concludes with a rather optimistic reference to German and South African national processes for recognition of trauma, noting the 'compassion, honesty and responsibility that these nations have embraced' (1355), and perhaps failing to acknowledge the complexity of these processes. Nevertheless his paper provides a framework for an important question about what it might mean to construct a mode of witnessing within the political field that might alleviate the effects of loss.

Paula Salvio provides an account of a process of witnessing that is sensitive to the complex risk entailed in a politics of making visible the invisible. She traces the Italian state's denial of 'systematic mafia infiltration into civil society', and interprets this failure as a betrayal of its role as a third, citing Bollas' suggestion that: 'Each state is a derivative of the parenting world that exists in the mind of its citizens' (in Salvio, 2014:99). This is the context for a biographical account of Letizia Battaglia's construction of a photographic archive of mafia violence. Salvio narrates Battaglia's career as a radical photojournalist, informed by a politics of participative spectatorship, and her documentation of approximately 100 mafia executions or disappearals in Palermo between 1978 and 1992. During this period 'Battaglia and her assistants were present at every major crime scene throughout the city' (103) and used their photographic archive to curate anti-mafia exhibitions - 'in public spaces, apart from state control and without profit' (104) - to engage the public and to make visible crimes that had previously been denied. Salvio argues that this process 'does not simply preserve a past, but reelaborates and re-inscribes history in ways that expand, disturb and ultimately reconstitute traumatic memories so they can be worked through' (102). She interprets the exhibitions as the basis for the development of a 'social protective shield', a mode of witnessing that constitutes social networks, here embodied in new networks of women led activism and engagement with culture in a mode of citizenship denied by the Italian state (100-101). 
However, Salvio's interviews with Battaglia also reveal the pain of her position as witness. Following the murder of two of the most important mafia prosecutors, Battaglia stopped photographing crime scenes. In the interview she said:

I was never again to take photographs of the dead and all that goes with it [...] I took the decision to never take another photograph of another dead body, of any more pain and certainly of no more Mafiosi. Today, exactly twenty years later, I can only deplore my weakness or indolence or whatever you want to call it. It was my duty to resist, to take more photographs and to consign them to a future memory. These photos which I never took actually hurt me more than those that I did... (in Salvio, 2014:111)

I wonder if we might relate Battaglia's position as witness, her direct confrontation with death, and the impossibility of resolution of her project, to Zizek's account of a political act in which the subject embodies the monstrosity of the Thing - the Thing that continues to be refused by the social fabric, the Thing that cannot be recognized in its excess, the Thing that is the cause of the most fundamental human passions. In recognizing both a possibility of reinscribing loss, but also the painful political and affective unpredictability of this process, Salvio's account illustrates the complexity of constituting an act of recognition of loss through a reconstruction of a 'live third' in the political field.

The juxtaposition of discussion of trauma related to the holocaust and violent crime with the losses related to articulations of positions within the left intelligentsia may be uncomfortable, but these should not be seen as distinct, separately unified contexts. If we understand, as psychoanalysis does, an originary traumatic loss to be the basis for subjectivity, and the unconscious to be the ongoing resonance of that originary loss, then we might perhaps ask: What narcissistic injury is repeated in libidinal articulations of positions on the political left? And the answer to this question may well suggest as yet unknown resonances between responses to losses that relate to political attachments, and experiences in other contexts in which a necessary relation to a third or a witnessing other has been broken or torn.

Gerson's and Salvio's accounts of the psychoanalytic and political witnessing of trauma also help to frame a question that drives discussion of loss within political theory: What kind of political act might constitute an appropriate response for the subjectivity that has been undermined by trauma? While it is necessary to distinguish between the clinical and political fields, one aim of bringing a psychoanalytic sensibility to bear on politics must be to inform both strategy and tactics. At a strategic level, the contrasting epistemologies of recognition, resignification and impossibility will inform our analysis of the field. At the tactical level, however, we need to explore the specificity of each instance, avoiding omniscient predictions of the movement of political and psychical relations. 


\section{Conclusion}

The conceptual distinctions introduced in Freud's theorization of mourning, melancholia and melancholic identification can be used to open up the meaning of grief within the political field. Freud's observation of the visceral ambivalence associated with melancholia provides a basis for later theorizations of the fundamental passion or narcissistic wound that underlies both the intransigence and the unpredictability of forces associated with loss. His conceptualization of complex mechanisms of internalization of both lost objects and cultural prohibitions, provides a basis for exploring processes of repudiation of excluded or marginalized identities. His identification of contrasting processes of internalization and externalization helps us to map the contrasting ways political energies are directed in the aftermath of loss. Most crucially, his formulation of unconscious object loss as a way of explaining intensely painful affective processes guides our understanding of relations to loss as a psychical layer embedded within political and economic relations.

In relation to the use of these ideas in political theory and analysis, the argument of this chapter has been that it is important to distinguish between epistemology and the empirical exploration of a specific case. Epistemological arguments indicate some of the political risks involved in the representation of loss, and the way such representation covers over the constitutive lack both in the object and in the social relations of its production. But it is important to remain open minded in exploring unconscious relations to a particular instance of loss, the specific yet undecidable effects of preserving or naming that loss, or of the refusal to name.

\section{References}

Brown, W. (1999) 'Resisting Left Melancholy', Boundary2, 26(3), 19-27

Butler, J. (1997) The Psychic Life of Power, California: Stanford University Press

Dubiel, H. (1990) 'Beyond Mourning and Melancholy on the Left', Praxis International, 10(34), 241-249

Eng, D. and Han, S. (2003) 'A Dialogue on Racial Melancholia', in D. L. Eng and D.

Kazanjian (eds) Loss: The Politics of Mourning, Berkley, London: University of California Press, 343-71

Evans, D. (1996) An Introductory Dictionary of Lacanian Psychoanalysis, London and New York: Routledge

Freud, S. (1923) 'The Ego and the Id', The Standard Edition of the Complete Psychological Works of Sigmund Freud Volume X1X: The Ego and the Id and Other Works, Vintage, The Hogarth Press and the Institute of Psychoanalysis, 2001, 3-66

Freud, S. (1957) 'Mourning and Melancholia' in The Complete Psychological works of

Sigmund Freud Volume X1V, London: The Hogarth Press and the Institute of Psychoanalysis, 243-257

Gerson, S. (2009) 'When the Third is Dead: Memory, Mourning and Witnessing in the Aftermath of the Holocaust', The International Journal of Psychoanalysis, 90, 1341-1357 Hill, P. (2002) Using Lacanian Clinical Technique: an introduction, Press for the Habilitation of Psychoanalysis 
Hook, D. (2014) 'Refuting melancholia: postures of melancholic identification in the Apartheid Archive', Rozenberg Quarterly, http://rozenbergquarterly.com/refuting-melancholiapostures-of-melancholic-identification-in-the-apartheid-archive/\#more-12085, accessed 27/08/17, no page numbers

Jay, M. (1992) 'Once More an Inability to Mourn? Reflextions on the Left Melancholy of Our Time', German Politics and Society, 27 (Fall 1992), 69-76

Lacan, J. (1977) 'The Direction of the Treatment and the Principles of its Power', in Ecrits: a selection, London and New York: Routledge, 250-310

Laplanche, J. (1999) Essays on Otherness, London and New York: Routledge

Mitscherlich, A. and Mitscherlich, M. (1967) The Inability to Mourn, New York: Grove Press 1975

Roy, S. (2009) 'Melancholic politics and the politics of melancholia: The Indian Women's movement', Feminist Theory, 10(3), 31-357

Salvio, P. M. (2014) 'Reconstructing memory through the archives: public pedagogy, citizenship and Letizia Battaglia's photographic record of mafia violence', Pedagogy, Culture and Society 22(1), 97-116

Segal, L. (2003) 'Theoretical Afflictions: Poor Rich White Folks Play the Blues', New Formations, 142-156

Wiegman, R. (2000) 'Feminism's Apocalyptic Futures', New Literary Histories, 31: 805-825

Zizek, S. 2000, 'Melancholy and the Act', Critical Inquiry, 26(4), 657-681 